\title{
Increased levels of serum interleukin-10 are associated with poor outcome in adult hemophagocytic lymphohistiocytosis patients
}

\author{
Yulan Zhou ${ }^{1,2}$, Fancong Kong ${ }^{1,2}$, Shixuan Wang ${ }^{1,2}$, Min Yu ${ }^{1,2}$, Yawen $\mathrm{Xu}^{1,2}$, Jing Kang ${ }^{1,2}$, Songtao $\mathrm{Tu}^{1,2}$ and \\ Fei Li $i^{1,2^{*}}$ (1)
}

\begin{abstract}
Background: Interleukin-10 (IL-10) is an independent factor for predicting adverse outcomes in pediatric patients with hemophagocytic lymphohistiocytosis $(H L H)$. However, little is known about its prognostic value in adult patients.

Methods: This single center retrospective study was conducted to explore the prognostic value of IL-10 in 101 adults newly diagnosed with HLH. The serum interleukin levels were quantitatively determined by chemiluminescence using cytokine profiling kits.

Results: Serum IL-10 levels were significantly increased in adult HLH patients. Elevated IL-10 levels was correlated with lower concentrations of hemoglobin ( $r=-0.279, P=0.005)$. IL-10 levels were significantly lower in patients with macrophage activation syndrome (MAS) than in those with infection-associated HLH (IAHS) and malignancyassociated HLH (MAHS) $(P=0.033, P=0.012)$. Patients with MAS had relatively longer survival than those with IAHS and MAHS $(P<0.001)$. Univariate analysis indicated that hemoglobin $<8.2 \mathrm{~g} / \mathrm{dL}$, platelets $<40 \times 10^{9} / \mathrm{L}$, lactate dehydrogenase $\geq 700 \mathrm{IU} / \mathrm{L}$, albumin $<28 \mathrm{~g} / \mathrm{L}$, post-treatment ferritin $>1050 \mu \mathrm{g} / \mathrm{L}$ and $\mathrm{IL}-10 \geq 129 \mathrm{pg} / \mathrm{mL}$ were poor prognostic factors for survival. However, multivariate analysis revealed that only high serum $\mathrm{LL}-10$ levels $(\geq 129 \mathrm{pg} / \mathrm{mL}$ ) at diagnosis and high post-treatment ferritin levels $(>1050 \mu \mathrm{g} / \mathrm{L})$ were independent risk factors for poor overall survival in adult HLH patients (HR: 4.087, 95\% Cl 2.064-8.090, $P<0.001$; HR 3.814, 95\% Cl 2.042-7.126, $P<0.001$, respectively).
\end{abstract}

Conclusions: Our results suggest that higher serum IL-10 levels might be a prognostic marker in adult HLH patients. Keywords: Hemophagocytic lymphohistiocytosis, IL-10, Adult, Prognosis, Overall survival

\section{Introduction}

Hemophagocytic lymphohistiocytosis (HLH, ORPHA: 158032) also known as hemophagocytic syndrome (HPS), is a rare and life-threatening hyperinflammatory syndrome characterized by pathologic immune activation $[1,2]$. Although HLH is predominant among children, it has been seen in adults of all ages. Based on the etiology, HLH is generally classified into two types: primary HLH

\footnotetext{
${ }^{*}$ Correspondence: $y x 021021 @$ sina.com

${ }^{1}$ Center of Hematology, The First Affiliated Hospital of Nanchang University, Nanchang 330006, Jiangxi, China

Full list of author information is available at the end of the article
}

(pHLH, ORPHA: 158038) and secondary HLH (sHLH, ORPHA: 158041). The former is caused by inherited gene defects and mainly occurs in infants. sHLH is associated with various medical conditions, including persistent infection, malignancy and autoimmune disease, and mainly occurs in adults [3]. In patients with HLH, immune cells (such as T cells, NK cells and macrophages) are usually aberrantly activated, leading to over secretion of cytokines (a cytokine storm), including interferon- $\gamma$ (IFN- $\gamma$ ), tumor necrosis factor- $\alpha$ (TNF- $\alpha$ ), interleukin-6 (IL-6) and IL-10. Cytokines play an important role in HLH [4]. Cytokines are associated with several clinical 
features, including prolonged fever, hepatosplenomegaly, cytopenia, coagulopathy, liver damage and hyperferritinemia. IL-10 is an important T helper 2 (Th2) cytokine expressed by numerous cells of the innate and adaptive arms of the immune system, identified as a molecule that limits inflammation and supports humoral immune responses [5]. It regulates the balance between inflammatory and humoral responses [6]. IL-10 may increase the progression of HLH. Yang et al. [7] discovered that IL-10 may contribute to cytopenias in HLH. Luo et al. [8] found that an increased level of IL-10 at diagnosis was an independent prognostic factor for predicting adverse outcomes in HLH. While most studies have focused on pediatric HLH, the role of IL-10 in adult HLH has rarely been reported. In this retrospective study, 101 Chinese adults with HLH were evaluated to determine the patterns of IL-10 and elucidate the relationship between IL-10 and the clinical characteristics of adult patients with HLH.

\section{Patients and methods Patients}

A total of 246 adult patients diagnosed with HLH between January 2015 and July 2020 at the First Affiliated Hospital of Nanchang University were reviewed retrospectively. The inclusion criteria for HLH patients were based on the HLH-2004 diagnostic guidelines [9]. Patients who had undergone cytokine measurement at diagnosis were considered. Demographic, clinical and laboratory data were recorded in all study participants. Exclusion criteria included exposure to immunosuppressive therapy before hospitalization and incomplete medical data. Follow-up was performed by reviewing medical records or making phone calls to the patients and their next of kin. The overall survival (OS) was estimated from the date of diagnosis to the date of death or last follow-up (July 5, 2020).

\section{Detection of cytokines}

Serum samples that were collected at diagnosis were used for the measurement of serum cytokines. The levels of IL-1 $\beta$, IL-8 and IL-10 were measured with cytokine profiling kits (Siemens Healthcare (Pty) Ltd.) using the Immulite ${ }^{\circledR} 1000$ Immunoassay System (Siemens Healthcare (Pty) Ltd) according to the manufacturer's instructions.

\section{Statistical analysis}

Numerical data were expressed as mean \pm SD or median with interquartile range. Categorical variables were expressed as numbers and percentages. Continuous variables were compared using the t test or Mann-Whitney $\mathrm{U}$ tests. Categorical variables were analyzed using the chi-square test or Fisher's exact test. Cytokines and routine laboratory parameters were defined as dichotomous variables based on median as the cut-off point according to previous studies [10]. The correlation between laboratory tests and various cytokines was determined by Spearman's rank correlation analysis. Survival outcomes were estimated using the Kaplan-Meier method and compared with the log-rank test. Multivariate Cox analysis (hazard ratios (HR) and $95 \% \mathrm{CI}$ ) was used to identify the independent prognostic variables for OS. A $P$ value $<0.05$ was considered statistically significant. Analyses were performed using SPSS software (version 24).

\section{Results}

\section{Characteristics of the enrolled participants}

Of 246 adult patients with HLH, 101 (55 males, 46 females) met the inclusion criteria for analysis. The median age was 49 years (range 18-89 years). Among the enrolled patients were 50 with infection-associated HLH (IAHS), 42 with malignancy-associated HLH (MAHS) and 9 with macrophage activation syndrome (MAS) (Additional file 1: Fig. 1). Patients in this cohort received the HLH-94/04 regimen, DEP regimen (doxorubicin-etoposide-methylprednisolone), or simple glucocorticoid therapy to control their symptoms. They received the treatment protocol best suited for the etiology of the HLH and supportive care. Epstein-Barr virus (EBV) was the most frequent etiology in IAHS patients (37/50, 74.0\%). Most MAHS patients presented with lymphoma (38/42, 90.5\%). The median follow-up time was 4.0 months (range $0.2-48.2$ months). At the time of the last follow-up (July 5, 2020), 58 patients (57.4\%) had died. Comparisons of demographic and clinical characteristics between HLH patients who survived and those who died are shown in Additional file 1: Table 1. Neutrophil counts, platelet counts and hemoglobin levels were significantly lower in patients who died compared to those who survived. The median OS of the entire cohort was 5.0 months. There were significant differences in prognosis among the three groups. Patients with MAS had relatively longer survival compared to those with IAHS and MAHS. Patients with MAHS had the shortest median survival (3.4 months, Fig. 1).

\section{Clinical manifestations and laboratory findings}

All patients presented with a history of one week to two months of high-grade fever (median 21 days, range 7 to 82 days), with temperature fluctuating from 38.5 to $41.0{ }^{\circ} \mathrm{C}$. Common clinical features of $\mathrm{HLH}$ included splenomegaly $(86 / 101,85.14 \%)$, hepatomegaly $(28 / 101,27.7 \%)$ and lymphadenopathy $(67 / 101$, 66.3\%). Cytopenias (affecting at least 2 of 3 lineages in the peripheral blood) were found in $58.4 \%(59 / 101)$ of 


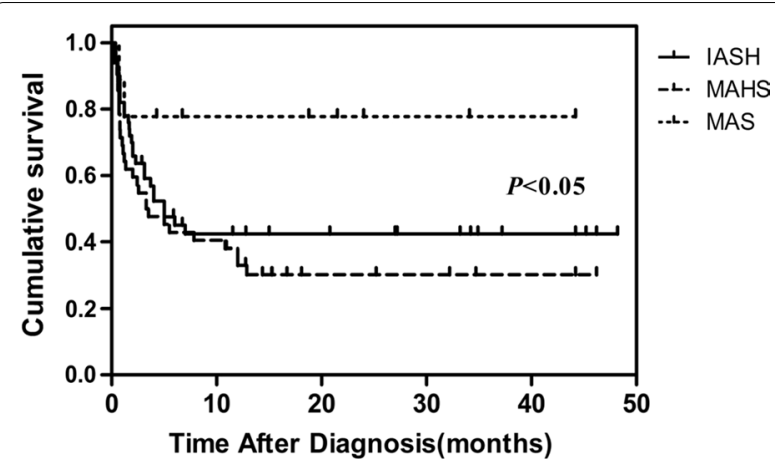

Fig. 1 Survival outcomes in adult secondary HLH patients. KaplanMeier curve showing the overall survival (OS) according to the cause of secondary HLH. Patients with macrophage activation syndrome (MAS) had the longer median survival time than those with infection-associated HLH (IAHS) and malignancy-associated HLH (MAHS) $(P<0.05)$

patients. Neutropenia $\left(<1.0 \times 10^{9} / \mathrm{L}\right)$, anemia $(<90 \mathrm{~g} / \mathrm{L})$ and thrombocytopenia $\left(<100 \times 10^{9} / \mathrm{L}\right)$ occurred in $53.5 \%$ (54/101), $57.4 \%$ (58/101), and $82.2 \%(83 / 101)$ of patients, respectively. Most patients presented with abnormal liver function: elevated aspartate aminotransferase (AST) (> $50 \mathrm{U} / \mathrm{L}, 70 / 101,69.3 \%)$, alanine aminotransferase (ALT) (>50 U/L, 73/101, 72.3\%), total bilirubin (>17.1 mmol/L, 43/101, 42.6\%) and lactate dehydrogenase (LDH) (>300 IU/L, 93/101, 92.1\%). Hyperferritinemia $(\geq 500 \mu \mathrm{g} / \mathrm{L})$ was documented in all patients, with $77.2 \%(78 / 101)$ of patients having a ferritin concentration higher than $2000 \mathrm{ng} / \mathrm{mL}$. Other laboratory findings included hypofibrinogenemia $(<1.5 \mathrm{~g} / \mathrm{L}$, 40/101, 39.6\%), hypertriglyceridemia (>3 $3 \mathrm{mmol} / \mathrm{L}$, $36 / 101,35.6 \%)$, prolonged activated partial thromboplastin time (10 s greater than control) (45/101, 44.6\%), prolonged prothrombin time (3 s greater than control) $(16 / 101,15.8 \%)$, elevated soluble CD25 (>2400 U/mL, $87 / 98,88.8 \%)$ and hemophagocytosis in the bone marrow $(57 / 97,58.8 \%)$.

\section{Cytokines}

As shown Additional file 1: Table 2 and Fig. 2A, the levels of IL-8 and IL-10 were significantly elevated in most patients. IL-1 $\beta$ was almost in the normal range. IL-10 levels were significantly higher in IAHS and MAHS patients compared with MAS patients $(P=0.033$, $P=0.012)$. IL-8 levels were significantly higher in IAHS patients than in MAS patients $(P=0.024)$. However, there was no significant difference in IL-1 $\beta$ levels among the three groups (Fig. 2B). Moreover, IL-10 levels were significantly higher in the group that died $(P=0.007$, Fig. 2C).

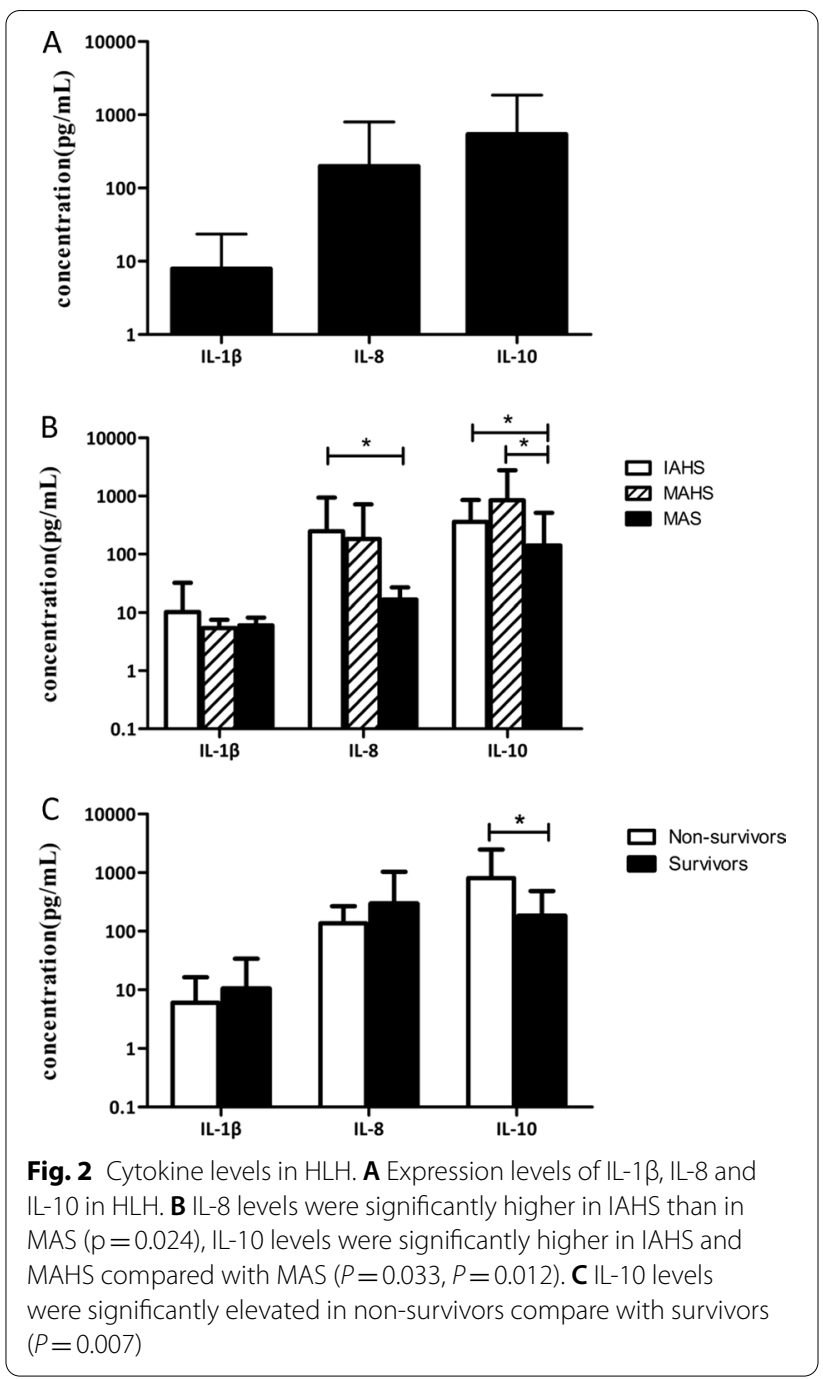

\section{Relationship between cytokines and routine laboratory parameters}

We investigated the relationship between serum IL-10 levels and various laboratory parameters such as the full blood count, liver function and ferritin. Serum IL-10 levels were significantly negatively correlated with the concentrations of hemoglobin $(\mathrm{r}=-0.279, P=0.005$, Table 1). IL-10 levels were significantly higher in HLH patients who had cytopenia of two or more lineages than in those who did not $(P=0.026)$.

\section{Relationship between cytokines and mortality}

Univariate and multivariate analyses were conducted to identify possible relationships between IL-10 and mortality. The cut-off values of cytokines and routine laboratory parameters were determined by their median values. Median OS was significantly shorter in HLH patients 
Table 1 Relations between IL-10 and clinical parameters in HLH

\begin{tabular}{lcl}
\hline Parameters & Correlation coefficient & $\boldsymbol{P}$ \\
\hline Neutrophil & -0.063 & 0.533 \\
Hemoglobin & -0.279 & $0.005^{*}$ \\
Platelet & -0.113 & 0.261 \\
Fibrinogen & 0.119 & 0.238 \\
Triglyceride & -0.031 & 0.760 \\
Lactate dehydrase & -0.053 & 0.600 \\
Albumin & -0.182 & 0.068 \\
Ferritin & -0.095 & 0.347 \\
IL-1 $\beta$ & -0.067 & 0.507 \\
IL-8 & -0.036 & 0.725 \\
\hline
\end{tabular}

*Indicates statistically significant values $(P<0.05)$

with IL- $10 \geq 129 \mathrm{pg} / \mathrm{mL}$ (3.12 months) than in those with IL- $10<129 \mathrm{pg} / \mathrm{mL}$ (not reached half deaths, $P<0.001$, Fig. 3C). However, no significant difference in OS was observed between groups for IL-1 $\beta$ (Fig. 3A) and IL-8 (Fig. 3B). The Kaplan-Meier survival analysis showed that patients with IAHS or MAHS and high serum IL-10 levels had poor OS $(P<0.001, P=0.001$, respectively, Additional file 1: Fig. 2). In univariate survival analysis, hemoglobin $<8.2 \mathrm{~g} / \mathrm{dL}$, platelet $<40 \times 10^{9} / \mathrm{L}$, albumin $<28 \mathrm{~g} / \mathrm{L}, \mathrm{LDH} \geq 700 \mathrm{U} / \mathrm{L}$, post-treatment ferritin $>1050 \mu \mathrm{g} / \mathrm{L}$ and IL-10 $\geq 129 \mathrm{pg} / \mathrm{mL}$ were associated with a worse outcome $(P=0.028 ; P=0.026 ; P=0.019$; $P=0.045 ; P<0.001, P<0.001$, respectively, Table 2$)$. However, in the multivariate Cox model, only IL-10 and posttreatment ferritin were independent predictors of poor OS $(P<0.001 ; P<0.001$, respectively, Table 3$)$.

\section{Discussion}

IL-10 is a pleomorphic cytokine with diverse phenotypic functions [11]. The expression of IL-10 is altered in numerous human diseases including cancer, autoimmune diseases and inflammatory diseases [12-14]. Osugi et al. and An et al. [15, 16] showed that serum concentrations of IL-10 increased in children with HLH and that IL-10 plays a critical role in the pathogenesis of HLH. However, the role of IL-10 in adult HLH remains unknown. The etiologic conditions associated with HLH in our cohort included rheumatic diseases in 9 patients, infections in 50 patients and malignancies in 42 patients. The most frequent triggers in our cohort were infections (49.5\%) and malignancies (41.6\%), which were consistent with other adult HLH cohorts that reported underlying diseases $[2,17,18]$. We demonstrated elevated serum levels of IL-10 in adult HLH patients. IL-10 levels were significantly higher in IAHS and MAHS patients compared with MAS patients. A

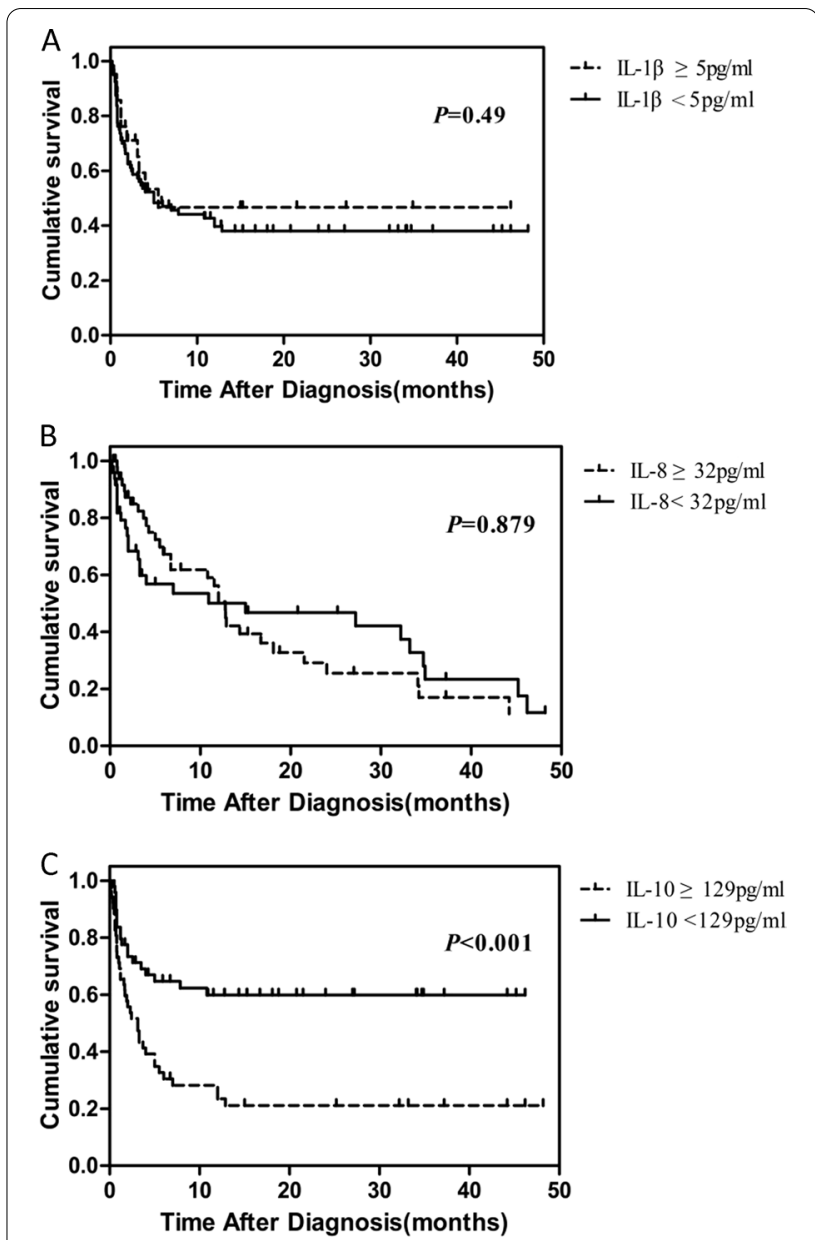

Fig. 3 Survival outcomes based on the serum cytokine level. Kaplan-Meier curve showing the OS based on the levels of IL-1 $\beta$, IL-8 and IL-10. A No statistically significant difference was observed in OS between HLH patients with IL-1 $\beta<5 \mathrm{pg} / \mathrm{mL}$ and those with $\mathrm{IL}-1 \beta \geq 5 \mathrm{pg} / \mathrm{mL}(P=0.49)$. B No statistically significant difference was observed in OS between HLH patients with IL-8 $<32 \mathrm{pg} / \mathrm{mL}$ and those with $\mathrm{IL}-8 \geq 32 \mathrm{pg} / \mathrm{mL}(P=0.879)$. $\mathbf{C}$ HLH patients with serum $\mathrm{LL}-10 \geq 129 \mathrm{pg} / \mathrm{mL}$ showed significantly worse OS compared to those with serum $\mathrm{IL}-10<129 \mathrm{pg} / \mathrm{mL}(P<0.001)$

recent study by Heper et al. [19] found that systemic levels of IL-10 were useful in predicting mortality in patients with sepsis. IL-10 levels were higher in patients who died compared to those who survived. Previous studies demonstrated that patients with MAHS and IAHS had a poorer outcome compared to patients with MAS [17, 20, 21]. Similar results were also observed in the present study where patients with MAS had a better outcome compared to those with other triggering conditions.

Correlation analysis revealed that IL-10 levels were closely correlated with hemoglobin levels $(P=0.005)$. In addition, IL-10 levels were significantly higher in 
Table 2 Univariate analysis of risk factors for OS in newly diagnosed adult HLH patients

\begin{tabular}{lllc}
\hline Prognostic factor & \multicolumn{3}{l}{ Overall } \\
\cline { 2 - 4 } & HR & $\mathbf{9 5 \% C l}$ & $\boldsymbol{P}$ \\
\hline Hemoglobin $<8.2 \mathrm{~g} / \mathrm{dL}$ & 1.853 & $1.069,3.213$ & $0.028^{*}$ \\
Platelets $<40 \times 10^{9} / \mathrm{L}$ & 1.798 & $1.072,3.015$ & $0.026^{*}$ \\
Fibrinogen $<2.0 \mathrm{~g} / \mathrm{L}$ & 0.871 & $0.520,1.458$ & 0.599 \\
$\mathrm{LDH} \geq 700 \mathrm{IU} / \mathrm{L}$ & 1.711 & $1.012,2.891$ & $0.045^{*}$ \\
Albumin $<28 \mathrm{~g} / \mathrm{L}$ & 2.341 & $1.148,4.775$ & $0.019^{*}$ \\
Triglycerides $>220 \mathrm{mg} / \mathrm{dL}$ & 0.997 & $0.571,1.741$ & 0.993 \\
Ferritin $>2000 \mu \mathrm{gg} / \mathrm{L}$ & 0.663 & $0.371,1.184$ & 0.165 \\
Post-treatment ferritin $>1050 \mu \mathrm{\mu g} / \mathrm{L}$ & 4.964 & $2.760,8.926$ & $<0.001^{*}$ \\
IL-1 $\beta \geq 5 \mathrm{pg} / \mathrm{mL}$ & 1.327 & $0.650,2.705$ & 0.437 \\
IL-8 $\geq 32 \mathrm{pg} / \mathrm{mL}$ & 1.312 & $0.780,2.207$ & 0.307 \\
IL-10 $\geq 129 \mathrm{pg} / \mathrm{mL}$ & 6.736 & $3.567,12.721$ & $<0.001^{*}$ \\
\hline
\end{tabular}

$\mathrm{HR}$, hazard ratio; $\mathrm{Cl}$, confidence interval

*Indicates statistically significant values

Table 3 Multivariate analysis of risk factors for OS in newly diagnosed adult HLH patients

\begin{tabular}{lllc}
\hline Prognostic factor & HR & $\mathbf{9 5 \%} \mathbf{C l}$ & $\boldsymbol{P}$ \\
\hline Hemoglobin $<8.2 \mathrm{~g} / \mathrm{dL}$ & 1.100 & $0.612,1.978$ & 0.750 \\
Platelets $<40 \times 10^{9} / \mathrm{L}$ & 1.589 & $0.914,2.764$ & 0.101 \\
$\mathrm{LDH} \geq 700 \mathrm{IU} / \mathrm{L}$ & 0.880 & $0.458,1.692$ & 0.702 \\
Albumin $<28 \mathrm{~g} / \mathrm{L}$ & 1.625 & $0.779,3.390$ & 0.196 \\
Post-treatment ferritin $>1050 \mu \mathrm{g} / \mathrm{L}$ & 3.814 & $2.042,7.126$ & $<0.001^{*}$ \\
IL-10 $\geq 129 \mathrm{pg} / \mathrm{mL}$ & 4.087 & $2.064,8.090$ & $<0.001^{*}$
\end{tabular}

$\mathrm{HR}$, hazard ratio; $\mathrm{Cl}$, confidence interval

*Indicates statistically significant values

HLH patients who had cytopenia of two or more lineages compared to those who did not. These results were similar to those of Yang et al. [7] who found that IL-10 might contribute to cytopenias in pediatric patients with HLH.

Previous studies have found that adverse outcomes are more common in HLH patients with certain pretreatment laboratory findings. A previous study in pediatric patients with secondary HLH found that severe hypoalbuminemia was an independent risk factor for 30-day mortality, and other biochemical parameters, including hemoglobin, fibrinogen and ferritin levels, did not influence the risk of death [22]. In another study involving 116 children with secondary HLH, Qiong et al. [23] found that low neutrophil count, low albumin level, high bilirubin level and high LDH level were significantly associated with a high risk of early death due to HLH. However, variables such as hemoglobin level, platelet count, fibrinogen level, triglyceride level and ferritin level were not significantly associated with early adverse outcomes. Sameer et al. [24] investigated adults with secondary HLH and found that high LDH levels, low albumin levels and high ferritin levels were associated with a worse prognosis. Anna et al. [25] found that various parameters, including low platelet counts, low hemoglobin levels, high alanine aminotransferase levels, high bilirubin levels, low albumin levels, high ferritin levels and low fibrinogen levels, were predictive of survival outcomes in adults with non-malignancy associated secondary HLH. Moreover, Zhou et al. [26] found that post-treatment serum ferritin $\geq 1050 \mu \mathrm{g} / \mathrm{L}$ may serve as an independent prognostic biomarker in adult HLH patients. Similar to previous studies, we found that low hemoglobin level $(<8.2 \mathrm{~g} / \mathrm{dL})$, low platelet counts $\left(<40 \times 10^{9} / \mathrm{L}\right)$, low albumin concentrations $(<28 \mathrm{~g} / \mathrm{L})$, high LDH levels $(\geq 700 \mathrm{U} / \mathrm{L})$ and high post-treatment serum ferritin levels $(\geq 1050 \mu \mathrm{g} / \mathrm{L})$ were associated with poor survival.

Cytokines have been shown to play important roles in the development of HLH [4]. Some cytokines were found to be correlated with prognosis of HLH. In a retrospective study of 155 patients, Lu et al. [27] demonstrated that IL-6, which contributes to acute systemic inflammatory response syndrome [28], was an independent negative predictor of HLH. Recent studies have indicated that IL-10 levels may be associated with adverse outcomes in pediatric HLH. Tang et al. [29] showed that significantly increased IL-10 was an early, specific and adverse prognostic risk factor for childhood HLH. Luo et al. [8] found that elevated IL-10 levels at diagnosis were independent prognostic factors for predicting death in children with HLH. Earlier this year, based on a small-sample study, Li et al. [30] showed that IL-10 was an important risk factor for early death in patients with sHLH. More interesting, they reported that high levels of IL-10 ( $\geq 16.73 \mathrm{pg} /$ $\mathrm{mL}$ ) predicted worse prognosis of sHLH. In the present study, we found that the level of IL-10 was higher in patients with poor survival. In addition, patients with IL- $10<129 \mathrm{pg} / \mathrm{mL}$ had longer OS compared to those with IL-10 $\geq 129 \mathrm{pg} / \mathrm{mL}$ regardless of the underlying etiologies, suggesting that high IL-10 levels were associated with mortality in adult HLH patients. Furthermore, a high serum IL-10 level was an independent risk factor for poor OS in adult HLH patients. However, unlike posttreatment serum ferritin, serum IL-10 levels can be used for prognostic evaluation before therapy.

It is well known that IL-10 mainly acts as a negative immune regulator in numerous diseases [11], as it inhibits the production of inflammatory mediators [31]. Our data suggest a possible role of IL-10 as an independent prognostic biomarker in adult HLH patients. Because HLH is a hyperinflammatory syndrome, we hypothesize that a regulatory feedback loop exists through which 
pro-inflammatory cytokines upregulate the anti-inflammatory cytokine IL-10 in HLH. Therefore, IL-10 may act as an 'alarm hormone', which reflects disease severity in HLH.

There are several limitations in the present study. First, it is a single center, retrospective cohort study. There were missing clinical data and patients who were lost to follow-up. Second, the study does not include cytokines such as IL-6, TNF- $\alpha$ and IFN- $\gamma$, which may also be potential prognostic indicators in HLH. Third, the relatively small number of patients might introduce a bias in our results. Therefore, further prospective multicentre studies with larger sample sizes are needed to validate our findings.

\section{Conclusions}

Our study suggests that elevated IL-10 $(\geq 129 \mathrm{pg} / \mathrm{mL})$ at diagnosis may be used as an independent prognostic marker in adult HLH patients to guide treatment strategies.

\section{Supplementary Information}

The online version contains supplementary material available at https://doi. org/10.1186/s13023-021-01973-4.

Additional file 1: Table S1. Demographic, laboratory data and $\mathrm{HLH}$ manifestations. Table S2. The expressions of cytokines in patients with HLH. Figure S1. Flowchart of patient recruitment and classification. Figure S2. Performance of serum IL-10 in patients with various etiologies. (A). Infection-associated HLH patients with high serum IL-10 levels showed significantly worse OS than those with low serum IL-10 levels $(P<0.001)$. (B). Malignancy-associated HLH patients with high serum IL-10 levels showed significantly worse OS than those with low serum IL-10 levels ( $P$ $=0.001$ )

\section{Acknowledgements}

We thank all of the patients and their families for their participation in this research.

\section{Authors' contributions}

$Z Y$ designed and performed the research, and also interpreted the data and drafted the manuscript; KF, WS, YM, XY, KJ and TS collected the clinical data; LF designed the study, analyzed and interpreted the data, and approved the final manuscript. All authors read and approved the final manuscript.

\section{Funding}

This work was financially supported by grants from the National Natural Science Foundation of China (81960043), National Natural Science Foundation of Jiangxi Province (20192ACB20030, 20202BAB216011) and Science Program of Health Commission of Jiangxi Province $(20165171,20203111)$.

\section{Availability of data and materials}

The data used to support the findings of this study are available from the corresponding author upon request.

\section{Declarations}

\section{Ethics approval and consent to participate}

The study was approved by the institutional ethics committees (No. 2020-ME095), and informed consent was obtained from all patients.
Consent for publication

Not applicable.

\section{Competing interests}

The authors declare no competing financial interests.

\section{Author details}

${ }^{1}$ Center of Hematology, The First Affiliated Hospital of Nanchang University, Nanchang 330006, Jiangxi, China. ${ }^{2}$ Institute of Hematology, Academy of Clinical Medicine of Jiangxi Province, Nanchang 330006, Jiangxi, China.

Received: 16 January 2021 Accepted: 19 July 2021

Published online: 04 August 2021

\section{References}

1. Skinner J, Yankey B, Shelton BK. Hemophagocytic lymphohistiocytosis. AACN Adv Crit Care. 2019;30(2):151-64.

2. Birndt S, Schenk T, Heinevetter B, Brunkhorst FM, Maschmeyer G, Rothmann F, et al. Hemophagocytic lymphohistiocytosis in adults: collaborative analysis of 137 cases of a nationwide German registry. J Cancer Res Clin Oncol. 2020;146(4):1065-77.

3. Bhatt NS, Oshrine B, An TJ. Hemophagocytic lymphohistiocytosis in adults. Leuk Lymphoma. 2019;60(1):19-28.

4. Wegehaupt O, Wustrau K, Lehmberg K, Ehl S. Cell versus cytokinedirected therapies for hemophagocytic lymphohistiocytosis (HLH) in inborn errors of immunity. Front Immunol. 2020;11:808.

5. lyer SS, Cheng G. Role of interleukin 10 transcriptional regulation in inflammation and autoimmune disease. Crit Rev Immunol. 2012:32(1):23-63.

6. Rutz S, Ouyang W. Regulation of interleukin-10 expression. Adv Exp Med Biol. 2016;941:89-116.

7. Yang $S L$, Xu XJ, Tang YM, Song H, Xu WQ, Zhao FY, et al. Associations between inflammatory cytokines and organ damage in pediatric patients with hemophagocytic lymphohistiocytosis. Cytokine. 2016;85:14-7.

8. Luo ZB, Chen YY, Xu XJ, Zhao N, Tang YM. Prognostic factors of early death in children with hemophagocytic lymphohistiocytosis. Cytokine. 2017:97:80-5.

9. Risma KA, Marsh RA. Hemophagocytic lymphohistiocytosis: clinical presentations and diagnosis. J Allergy Clin Immunol Pract. 2019;7(3):824-32.

10. Song EJ, Lee CW, Jung SY, Kim BN, Lee KS, Lee S, et al. Prognostic impact of skeletal muscle volume derived from cross-sectional computed tomography images in breast cancer. Breast Cancer Res Treat. 2018;172(2):425-36.

11. Neumann C, Scheffold A, Rutz S. Functions and regulation of T cellderived interleukin-10. Semin Immunol. 2019;44:101344.

12. Kany S, Vollrath JT, Relja B. Cytokines in inflammatory disease. Int J Mol Sci. 2019;20(23):6008.

13. Ouyang W, Rutz S, Crellin NK, Valdez PA, Hymowitz SG. Regulation and functions of the IL-10 family of cytokines in inflammation and disease. Annu Rev Immunol. 2011;29:71-109.

14. Wang $X$, Wong K, Ouyang W, Rutz S. Targeting IL-10 family cytokines for the treatment of human diseases. Cold Spring Harb Perspect Biol. 2019;11(2):a028548

15. Osugi Y, Hara J, Tagawa S, Takai K, Hosoi G, Matsuda Y, et al. Cytokine production regulating Th1 and Th2 cytokines in hemophagocytic lymphohistiocytosis. Blood. 1997;89(11):4100-3.

16. An Q, Hu SY, Xuan CM, Jin MW, Ji Q, Wang Y. Interferon gamma and interleukin 10 polymorphisms in Chinese children with hemophagocytic lymphohistiocytosis. Pediatr Blood Cancer. 2017;64(9):e26505.

17. Li F, Yang Y, Jin F, Dehoedt C, Rao J, Zhou Y, et al. Clinical characteristics and prognostic factors of adult hemophagocytic syndrome patients: a retrospective study of increasing awareness of a disease from a singlecenter in China. Orphanet J Rare Dis. 2015;10:20.

18. Wang YN, Wang Z, Wu L, Cen XN, Li BT, Ning F, et al. A multicenter retrospective analysis of diagnosis and treatment of 72 hemophagocytic syndrome patients. Zhonghua Xue Ye Xue Za Zhi. 2009;30(12):793-8.

19. Heper Y, Akalin EH, Mistik R, Akgöz S, Töre O, Göral G, et al. Evaluation of serum C-reactive protein, procalcitonin, tumor necrosis factor alpha, and interleukin-10 levels as diagnostic and prognostic parameters in patients 
with community-acquired sepsis, severe sepsis, and septic shock. Eur J Clin Microbiol Infect Dis. 2006;25(8):481-91.

20. Huang W, Wang Y, Wang J, Zhang J, Wu L, Li S, et al. Clinical characteristics of 192 adult hemophagocytic lymphohistiocytosis. Zhonghua Xue Ye Xue Za Zhi. 2014;35(9):796-801.

21. Brito-Zeron P, Kostov B, Moral-Moral P, Martínez-Zapico A, Díaz-Pedroche $C$, Fraile $G$, et al. Prognostic factors of death in 151 adults with hemophagocytic syndrome: etiopathogenically driven analysis. Mayo Clin Proc Innov Qual Outcomes. 2018;2(3):267-76.

22. Oguz MM, Sahin G, Altinel Acoglu E, Polat E, Yucel H, Oztek Celebi FZ, et al. Secondary hemophagocytic lymphohistiocytosis in pediatric patients: a single center experience and factors that influenced patient prognosis. Pediatr Hematol Oncol. 2019;36(1):1-16.

23. Bin $\mathrm{Q}$, Gao JH, Luo JM. Prognostic factors of early outcome in pediatric hemophagocytic lymphohistiocytosis: an analysis of 116 cases. Ann Hematol. 2016;95(9):1411-8.

24. Parikh SA, Kapoor P, Letendre L, Kumar S, Wolanskyj AP. Prognostic factors and outcomes of adults with hemophagocytic lymphohistiocytosis. Mayo Clin Proc. 2014;89(4):484-92.

25. Hayden A, Park S, Giustini D, Lee AY, Chen LY. Hemophagocytic syndromes (HPSs) including hemophagocytic lymphohistiocytosis $(H L H)$ in adults: a systematic scoping review. Blood Rev. 2016;30(6):411-20.
26. Zhou J, Zhou J, Shen DT, Goyal H, Wu ZQ, Xu HG. Development and validation of the prognostic value of ferritin in adult patients with hemophagocytic lymphohistiocytosis. Orphanet J Rare Dis. 2020;15(1):71.

27. Lu M, Xie Y, Guan X, Wang M, Zhu L, Zhang S, et al. Clinical analysis and a novel risk predictive nomogram for 155 adult patients with hemophagocytic lymphohistiocytosis. Ann Hematol. 2021 May 12. Epub ahead of print.

28. Tanaka T, Narazaki M, Kishimoto T. Interleukin (IL-6) immunotherapy. Cold Spring Harb Perspect Biol. 2018;10(8):a028456.

29. Tang Y, Xu X, Song H, Yang S, Shi S, Wei J, et al. Early diagnostic and prognostic significance of a specific Th1/Th2 cytokine pattern in children with hemophagocytic syndrome. Br J Haematol. 2008;143(1):84-91.

30. Li Z, Liu J, Man Y, Liu F, Gao L, Hu P, et al. Analysis of cytokine risk factors in the early death of patients with secondary phagocytic lymphocytic histiocytosis. Am J Transl Res. 2021;13(4):2388-98.

31. Sabat R, Grütz G, Warszawska K, Kirsch S, Witte E, Wolk K, et al. Biology of interleukin-10. Cytokine Growth Factor Rev. 2010;21(5):331-44.

\section{Publisher's Note}

Springer Nature remains neutral with regard to jurisdictional claims in published maps and institutional affiliations.
Ready to submit your research? Choose BMC and benefit from:

- fast, convenient online submission

- thorough peer review by experienced researchers in your field

- rapid publication on acceptance

- support for research data, including large and complex data types

- gold Open Access which fosters wider collaboration and increased citations

- maximum visibility for your research: over $100 \mathrm{M}$ website views per year

At BMC, research is always in progress.

Learn more biomedcentral.com/submissions 